\title{
THE EFFECT OF FLUORIDE CONTAINING TOOTHPASTE ON THE ELECTROCHEMICAL BEHAVIOR OF 316L STAINLESS STEEL FOR DENTISTRY APPLICATIONS IN THE HUMAN SALIVA
}

\author{
Veaceslav NEAGA, Lidia BENEA \\ Competences Center: Interfaces-Tribocorrosion-Electrochemical Systems \\ "Dunarea de Jos" University of Galati, Romania \\ e-mail: lidia.benea@ugal.ro
}

\begin{abstract}
The study aims to investigate the effect of fluorinated toothpaste added in Fusayama-Meyer saliva in order to evaluate the electrochemical behavior of $316 \mathrm{~L}$ SS for dentistry applications.

For electrochemical behavior in situ electrochemical measurements such as: Open circuit potential (OCP), Linear Polarization (PL), Potentiodynamic Polarization (PD) and Electrochemical Impedance Spectroscopy (EIS) were applied. The results show a comparative analysis of the electrochemical behavior and corrosion resistance of 316L-SS in human saliva containing high fluoride toothpaste for dentistry applications. From the electrochemical results it can be concluded that the addition of fluoride toothpaste in Fusayama-Meyer saliva decreases the corrosion resistance of $316 \mathrm{~L}-\mathrm{SS}$ and therefore will reduce the lifetime of dentistry structures or devices.
\end{abstract}

KEYWORDS: orthodontic devices; 316L stainless steel; corrosion; electrochemical methods; saliva; toothpaste

\section{Introduction}

Stainless steel AISI 300th series of steels has high rates of corrosion resistance, strength and flexibility. They can be used with equal success in the food [1], pharmaceutical industries [2] or dental medicine [3]. However, in recent years, interest in AISI 316L (316L-SS) has increased from economic considerations (low cost, reasonable strength, corrosion resistance and biocompatibility) [4-5]. For example, in dentistry, it is used in a variety of applications (endodontic files in root canal therapy, sterilized instruments, metal posts in root canal treated teeth, arch wires, temporary crowns and brackets in orthodontics) [5]. This can be attributed primarily to corrosion resistance. Moreover, this resistance concerns not only atmospheric phenomena, but also acidic and alkaline media present in the oral cavity of healthy or sick patients.

In the context of the mechanical systems, making orthodontic metallic devices and their subsequent use in the oral cavity for a long time, requires utmost attention to the corrosive process of the material in aggressive environments due to factors such as salivary $\mathrm{pH}$, temperature, quantity of microelements $(\mathrm{F}, \mathrm{Cl})$ and enzymatic activity of bacterial micro flora.

Consequences of the corrosive process represented by surface modification and increased roughness cause a decrease in the mechanical strength of the alloys in time [6-7].

Last but not least, the recommendations of the specialists regarding oral hygiene as a preventative treatment of orthodontic treatment should be considered, where dental brushing is the basis of the process of removing food debris and plaque accumulated around orthodontic appliances to counteract the development of dental and periodontal pathologies [8]. Among other things, the latest research demonstrates a better preventative result of diurnal and nocturnal brushing with Fluorine 5000 ppm fluoride toothpaste than the combination of once daily fluoride toothpaste $1000 \mathrm{ppm}$ and rinse with sodium fluoride $500 \mathrm{ppm}$ [9].

However, other studies appreciate the presence of sodium fluoride in products of oral hygiene, as initiator of the corrosive process by the formation of hydrofluoric acid (HF) after reacting of fluorine and hydrogen ions produced by bacteria, with role to destroy the protective oxide layer on the surface 
orthodontic metal components [6, 10-11] or increase friction force [12]. In some recent studies, corrosion mechanisms of stainless steel have been examined in various solutions, including different artificial saliva [5, 13-16].

The purpose of this work is to evaluate the corrosion resistance of AISI 316L stainless steel in terms of their suitability for dentistry applications in two different artificial saliva with Fluoride as 1400 ppm toothpaste and non-fluoride one. Comparative corrosion evaluation was performed using electrochemical techniques as open circuit potential, potentiodynamic measurements and electrochemical impedance spectroscopy measurements at free potential. In the literature there is a lack of information regarding the influence of fluorinated toothpaste on the corrosion behavior of stainless steel in saliva for dentistry applications. This research work aims to investigate the effect of fluorinated toothpaste added to human saliva on the corrosion behavior of $316 \mathrm{~L}$ stainless steel used in orthodontic applications.

\section{Materials and methods}

\subsection{Materials and methodology}

In this experimental study, the samples of AISI 316L stainless steel purchased from Direct Line Inox, Bucharest in a form of sheets with the following dimensions $250 \mathrm{~mm} \times 250 \mathrm{~mm}$ and $1.5 \mathrm{~mm}$ thickness, with compositions in mass fractions as shown in Table 1 .

Table 1. Chemical composition in mass percent of the AISI 316L stainless steel

\begin{tabular}{|c|c|c|c|c|c|c|c|}
\hline \multicolumn{7}{|c|}{ Chemical compositions (wt\%) } \\
\hline $\begin{array}{c}\text { Chemical } \\
\text { element }\end{array}$ & $\mathbf{C}$ & $\mathbf{M n}$ & $\mathbf{S i}$ & $\mathbf{M o}$ & $\mathbf{N i}$ & $\mathbf{C r}$ & $\mathbf{F e}$ \\
\hline 316L SS & $\leq 0.03$ & $\leq 2$ & 1 & $2.0-2.5$ & $11-14$ & $16.5-18.5$ & Bal. \\
\hline
\end{tabular}

Each group of the samples AISI 316L SS samples were investigated to one of two media: SFM (human Saliva Fusayama-Meyer) [4, 17] and SFM mixed with fluoride-containing toothpaste. The chemical composition of Fusayama Meyer saliva can be seen in Table 2 .

Composition of fluorinated toothpaste (ParodontaxR) (1400 ppm $\mathrm{F}^{-}$ion) describes these components: Sodium Bicarbonate, Aqua, Glycerin, Cocamidopropyl Betaine, Alcohol, Krameria Triandra (Ratanhia), Mentha Piperita Oil, Mentha Arvensis Oil, Echinacea Purpurea, Commiphora Myrrha, Chamomilla Recutita, Salvia Officinalis (Sauge) Oil,
Sodium Fluoride, Sodium Benzoate, Xanthan Gum, Sodium Saccharin, Limonene, CI 77491.

This study also involves a method of calculating the physiological proportions of human saliva and fluorinated toothpaste, used in another research field, where it proposes a mixture of paste and solution in a ratio of $1: 4(\mathrm{w} / \mathrm{v})[6]$.

In this experiment it was used a solution of human saliva in volume of $150 \mathrm{~mL}$ mixed with $37.5 \mathrm{~g}$ fluorinated toothpaste. The reported volume between saliva and toothpaste represents the quantity of oral fluid exposed to a healthy person during a 3-4 minute dental brushing, where the average normal stimulated salivary secretion is $1 \mathrm{~mL} /$ minute [18].

Table 2. Chemical composition of Fusayama-Meyer saliva

\begin{tabular}{|c|c|c|}
\hline Nr. crt. & Compound & Saliva Fusayama Meyer [g/L] \\
\hline $\mathbf{1}$ & $\mathrm{NaCl}$ & 0.4 \\
\hline $\mathbf{2}$ & $\mathrm{KCl}$ & 0.4 \\
\hline $\mathbf{3}$ & $\mathrm{CaCl}_{2}$ & 0.8 \\
\hline $\mathbf{4}$ & $\mathrm{NaH}_{2} \mathrm{PO}_{4} * 12 \mathrm{H}_{2} \mathrm{O}$ & 0.79 \\
\hline $\mathbf{5}$ & $\mathrm{UREA}$ & 1 \\
\hline $\mathbf{6}$ & $\mathbf{p H}$ & $\mathbf{5 . 7}$ \\
\hline
\end{tabular}

The samples used as the working electrodes were cut into $25 \times 25 \mathrm{~mm}$ plate with $1.5 \mathrm{~mm}$ thickness and solder with an electrical cable to have electrical contact and insulated with epoxy resin leaving a working area exposed for electrochemical tests resulted at $225 \mathrm{~mm}^{2}(15 \mathrm{~mm} \times 15 \mathrm{~mm})$. The sides and the conductive cable contact area were protected by an inert resin layer. The electrochemical measurements were carried out with three-electrode electrochemical station in a $250 \mathrm{~mL}$ cell and managed 


\section{THE ANNALS OF “DUNAREA DE JOS” UNIVERSITY OF GALATI \\ FASCICLE IX. METALLURGY AND MATERIALS SCIENCE \\ $\mathrm{N}^{\circ} .4$ - 2020, ISSN 2668-4748; e-ISSN 2668-4756 \\ Article DOI: $\underline{\text { https://doi.org/10.35219/mms.2020.4.07 }}$}

by hardware device VoltaLab PGZ 100 with software controlled VoltaMaster 4 by a personal computer. In the electrochemical cell, the AISI 316L stainless steel work electrode (WE) and the auxiliary electrode (AE) consisting of a Pt-Rh grid were spatially arranged parallel and on the same distances between electrodes. The reference electrode $\mathrm{Ag} / \mathrm{AgCl}$ with $\mathrm{KCl}$ saturated solution $(\mathrm{E}=+199 \mathrm{mV})$ is placed halfway between WE and AE [19].

Before each experiment, the AISI 316L stainless steel samples were cleaned with ethanol $99.3 \%$ after then rinsed in distilled water and dried. For each experiment it was established a volume of $150 \mathrm{~mL}$ solution. All experiments have been conducted at room temperature of $25^{\circ} \mathrm{C}$.

The electrochemical methods were focused on the following corrosion tests: Open circuit potential (OCP) measured for a period of 720 minutes and monitored over time until it reached a stable state value relative to the $\mathrm{Ag} / \mathrm{AgCl}$ reference electrode (RE).

The linear and potentiodynamic polarization were performed after 28 hours of immersion of the sample and consisted of imposing a potential amplitude of $\pm 50 \mathrm{mV}$ around free potential or imposing a variable potential (range from $-1 \mathrm{~V}$ to +1.5 V/Ag/AgCl) between the working electrode (WE) and the reference electrode (RE) with a scan rate: $1 \mathrm{mV} / \mathrm{s}$.

Measurements of Electrochemical Impedance Spectroscopy makes it possible, without disturbing the nature of the flow of operation, to study the kinetics and mechanism of corrosion processes, passivation mode and the formation of protective films on metals, as well as the adsorption behavior of inhibitors. Electrochemical Impedance Spectroscopy (EIS) after 12 hours of immersion were performed in a spectrum value from $100 \mathrm{kHz}$ to $1 \mathrm{mHz}$, where the alternate applied signal has a sine wave amplitude of $10 \mathrm{mV}$ with a frequency per decade of $10 \mathrm{~Hz}$ and 0.1 $\mathrm{s}$ delay before integration. All recorded EIS measurements were analyzed as Nyquist and Bode diagrams using the ZView 3.4e software for fitting the experimental data. To verify reproducibility, each experiment was repeated four times.

\section{Results and discussions}

\subsection{Open circuit potential (OCP)}

The variation of the open circuit potential is used as a criterion for determining the corrosion behavior tendency of a material in an oxidizing environment. OCP measurements of AISI 316L stainless steel immersed in saliva Fusayama Meyer and SFM with fluorinated toothpaste are presented in Figure 1.

The physico-chemical characteristics of prepared solutions used for corrosion investigations were measured with a multi-parameter analysis device CONSORT C-533 were used. The results are displayed in Table 3.

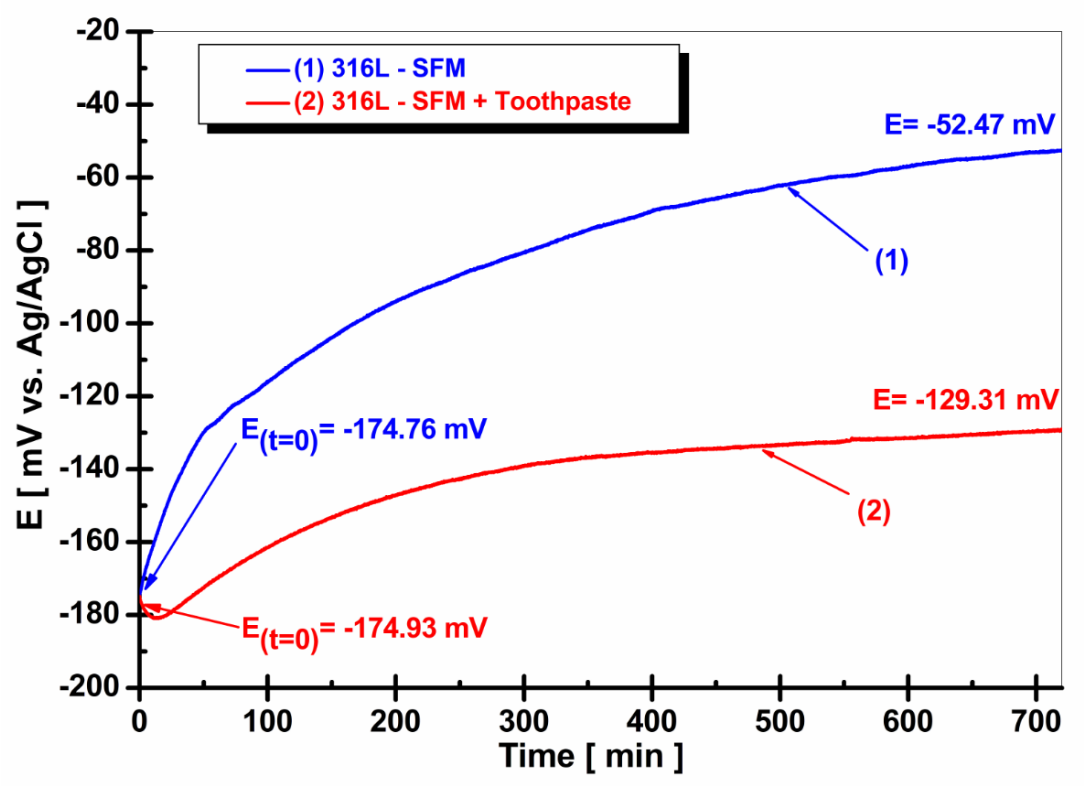

Fig. 1. Evolution of open circuit potential during 12 hours of immersion of $316 \mathrm{~L}$ stainless steel in: (1) Saliva Fusayama-Meyer; (2) Saliva Fusayama-Meyer with fluorinated toothpaste 
Table 3. Characteristics of Fusayama Meyer saliva

\begin{tabular}{|c|c|c|c|}
\hline Simulated Body Fluid & pH & Salinity & $\begin{array}{c}\text { Conductivity } \\
{[\mathbf{m S / c m}]}\end{array}$ \\
\hline Saliva Fusayama Meyer & 5.7 & 1.3 & 2.6 \\
\hline Fusayama Meyer + Fluorinated toothpaste & 8.1 & 26.3 & 42 \\
\hline
\end{tabular}

From Figure 1, the open circuit potential recorded for 12 hours in two different $\mathrm{pH}$ solutions (5.7 and 8.1) show that the starting values or the immersion time values of open circuit potential are very close, respectively $-174.76 \mathrm{mV}$ vs. $\mathrm{Ag} / \mathrm{AgCl}$ in SFM with $\mathrm{pH} 5.7$ and $-174.93 \mathrm{mV}$ vs. $\mathrm{Ag} / \mathrm{AgCl}$ in SFM with toothpaste ( $\mathrm{pH}$ 8.1). The transition tendency to passive potentials in SFM with $\mathrm{pH} 5.7$ is at more positive values reaching a steady state value of $-52.47 \mathrm{mV}$ vs. $\mathrm{Ag} / \mathrm{AgCl}$. Comparing to the open circuit potential in fluorinated medium with $\mathrm{pH} 8.1$, the passive potential is established to more negative values and the steady state value is reached at -129.31 $\mathrm{mV}$ vs. $\mathrm{Ag} / \mathrm{AgCl}$ at the end of measurement.

In order to determine the influence of the $\mathrm{pH}$ factor besides $\mathrm{F}^{-}$ion, the samples were tested with other electrochemical methods.

\subsection{Linear polarization (LP)}

From the linear polarization diagram, quantitative information on the polarization resistance and corrosion currents can be extracted from the curve slope according to the Stern- Geary equation [5].

$$
i_{c o r}=\frac{B}{R_{p}}
$$

While the Stern-Geary parameter B was calculated using equation:

$$
B=\frac{b_{a}\left|b_{c}\right|}{2.303\left(b_{a}+\left|b_{c}\right|\right)}
$$

where: icor $=$ corrosion current density; $\mathrm{Rp}=$ polarization resistance; ba and bc are the Tafel slopes for anodic and cathodic reactions on linear polarization curves. The increase of polarization resistance means the decrease of corrosion current, therefore the decrease of corrosion rate.

In Figure 2, the linear polarization curves of AISI 316L SS are shown. It is observed that the corrosion potential (Ecor) for stainless steel immersed in Fusayama Meyer saliva mixed with fluorinated toothpaste with $\mathrm{pH} 8.1$ is shifted to more negative value, $\mathrm{mV}$ vs. $\mathrm{Ag} / \mathrm{AgCl}$ as compared with corrosion potential revealed by stainless steel in Fusayama Meyer without toothpaste with $\mathrm{pH} 5.7, \mathrm{mV}$ vs. $\mathrm{Ag} / \mathrm{AgCl}$.

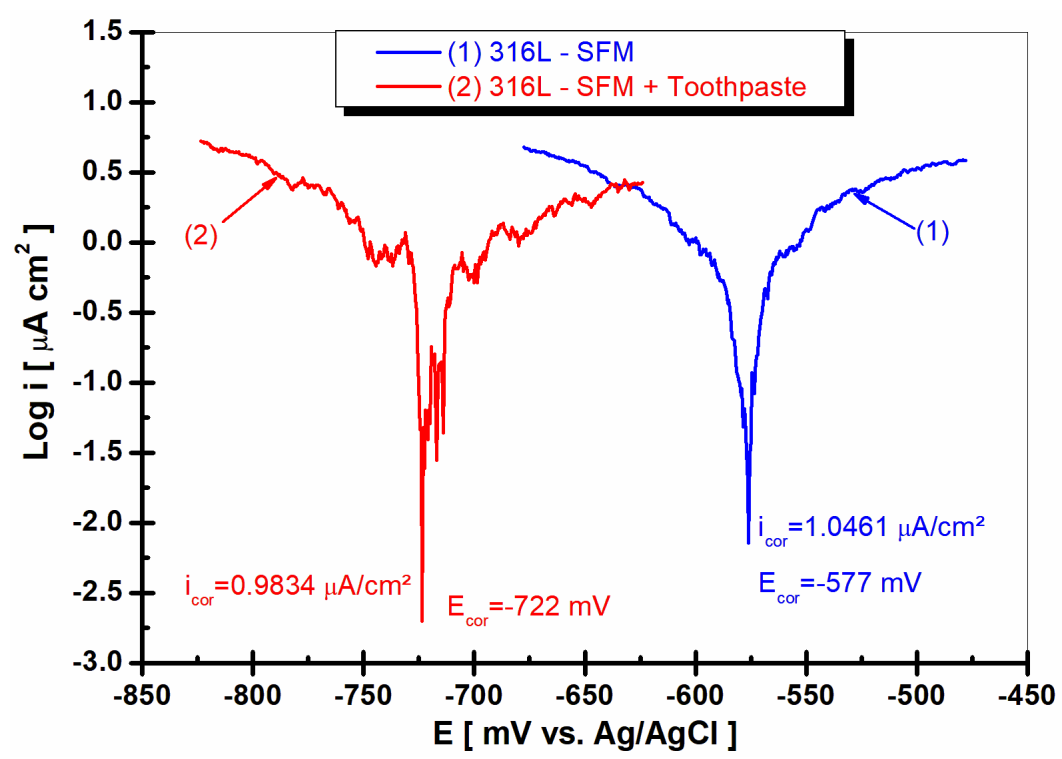

Fig. 2. Linear polarization diagrams around free potential of 316L stainless steel in: (1) Saliva Fusayama-Meyer; (2) Saliva Fusayama-Meyer with fluorinated toothpaste at a sweep rate of $1 \mathrm{mV} / \mathrm{s}$ 
The corrosion current density reveals about the same values for stainless steel, both values being in the same order of magnitude as it can be seen in Fig. 2 .

\subsection{Potentiodynamic polarization}

Potentiodynamic polarization diagrams were performed in Fusayama Meyer solution with and

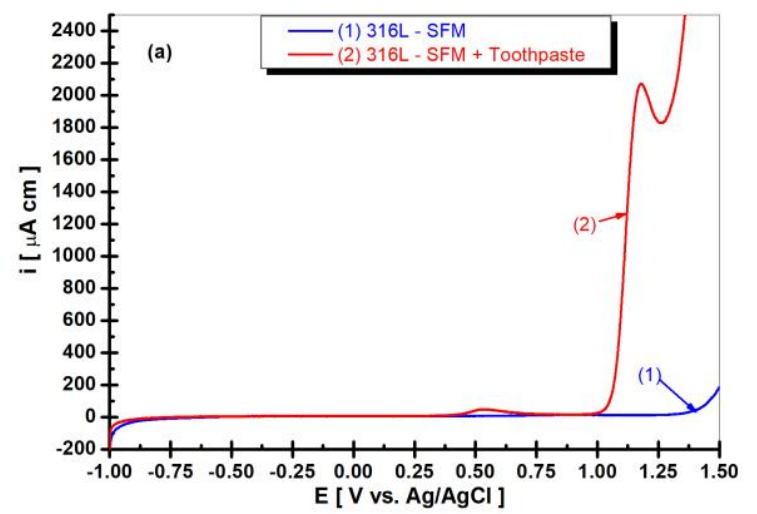

without fluorinated toothpaste. The results are presented in Figure 3 (a, b). Figure 3a show the entire domain of current density and potential while Figure $3 b$ show a zoom in the range of lower current densities in order to observe better the passive domains of stainless steel immersed in saliva SFM and saliva SFM mixed with toothpaste.

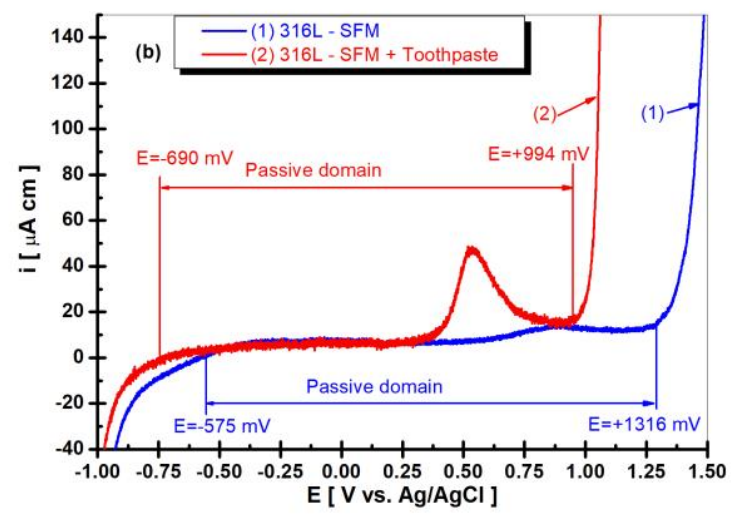

Fig. 3. Potentiodynamic polarization diagrams of 316L stainless steel performed at a sweep rate of 1 mV/s in: (1) Saliva Fusayama-Meyer; (2) Saliva Fusayama-Meyer with fluorinated toothpaste

As it is shown in Figure 3 a the current density in transpassive domain of stainless steel immersed in saliva mixed with fluorinated toothpaste increases rapidly having higher values as compared with the current density of stainless steel in transpassive domain corresponding to Fusayama Meyer saliva without toothpaste. The passive domain of stainless steel immersed in Fusayama Meyer solution is wider extending over $1316 \mathrm{mV}$ as it can be seen in Figure $3 \mathrm{~b}$. When human saliva is mixed with fluorinated toothpaste the passive domain of $316 \mathrm{~L}$ stainless steel becomes narrower stretching only on $994 \mathrm{mV}$. It appears also that localized corrosion through passive film occurs when saliva is mixed with fluorinated toothpaste, Figure 3b, diagram (2).

\subsection{Electrochemical impedance spectroscopy}

In this section, the results obtained by the impedance spectroscopy method complement the open circuit and polarization measurements. To more clearly identify the features of the electrochemical corrosion behavior of AISI 316L stainless steel in human saliva environment with and without addition of fluorinated toothpaste, tests were performed to measure the impedance of an electrochemical cell when a small amplitude sinusoidal voltage is applied to it. As a result of the EIS measurements and its graphical dependence of $Z=f(\omega)$, where $\omega$ is the angular frequency, in the coordinates of complex ohmic plane, the real component $(\operatorname{Re} \mathrm{Z})$ is plotted along the $\mathrm{x}$ axis, and the imaginary component of the resistance (- Im Z) is plotted along the $y$ axis [20]. Figure 4 shows the impedance spectrum in the Nyquist graphs, with a higher specific resistance of 316L stainless steel in Fusayama-Meyer saliva, R= 4370 as compared with the specific resistance obtained in human saliva mixed with fluoride toothpaste, $\mathrm{R}=1200 \mathrm{kohm} \cdot \mathrm{cm}^{2}$.

To simulate and fit the EIS experimental results an equivalent electrical circuit model is proposed to express the interface of stainless steel in contact with human saliva. Characterizing the corrosion processes occurring on their surface. The impedance is expressed by the following equation [21-22]:

$$
Z_{C P E}=\frac{1}{Q(j \omega)^{\alpha}}
$$

where: $\mathrm{Q}$ is the frequency-independent real constant of the CPE in $\mathrm{F} \mathrm{cm}-2 \mathrm{~s} \alpha-1, \omega$ is the angular frequency $(\omega=2 \pi f)$ in $\operatorname{rad~} \mathrm{s}^{1-}, \mathrm{f}$ is frequency $\mathrm{Hz}, j$ is the imaginary number, $j=\sqrt{ }-1, \alpha$ is related to the angle of rotation of a purely capacitive line on the complex plane plots. 


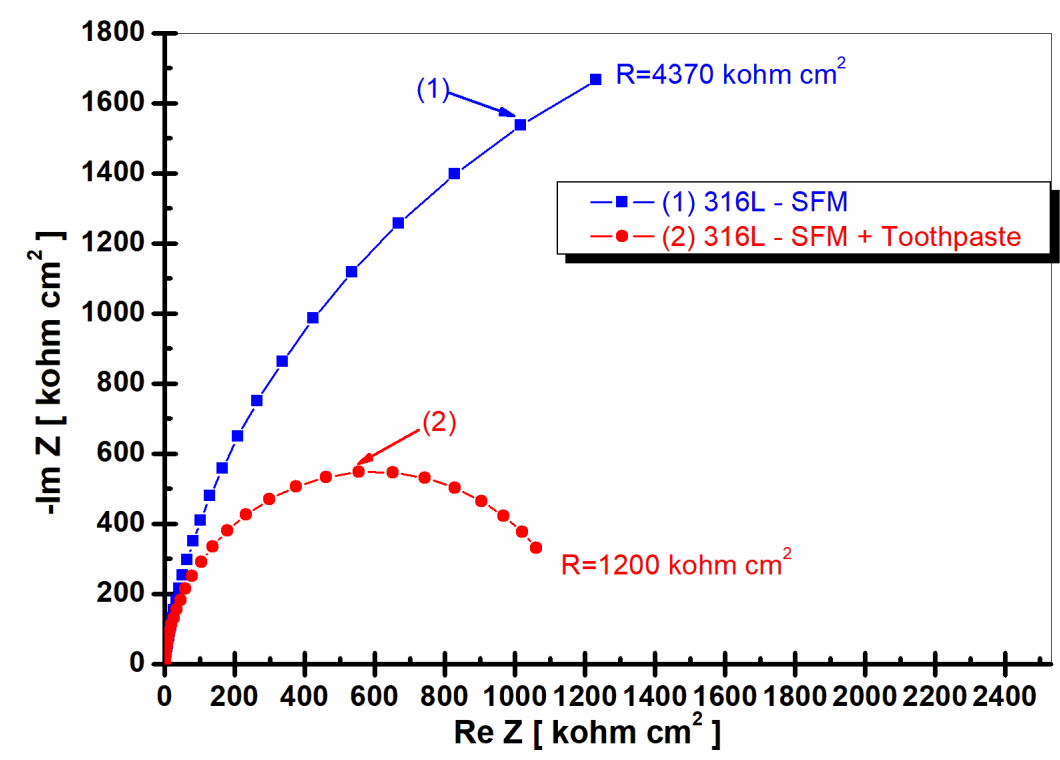

Fig. 4. Nyquist graphs of the impedance results for the AISI 316L stainless steel immersed in: (1) Saliva Fusayama-Meyer; (2) Saliva Fusayama-Meyer with fluorinated toothpaste

The time constant dispersion, CPE is attributed to capacity dispersion or to capacity change with frequency. For this research work the constant phase elements (CPE) could express the irregularity of the electrode surface. The value of $\alpha$ is associated to the non-uniform distribution of current as the result of surface inhomogeneity (roughness, structure, defects). The parameter $\alpha$ can takes values from -1 to 1 [23]. In the case when $\alpha \neq 1$, the system reveals a behavior that attributes heterogeneity or the continuously distributed time constants for charge-transfer reactions [5].

The modified Randles circuit with two-time constants, with schematic presentation in Fig. 5, was proposed to fit the EIS experimental results. In this circuit $R_{\mathrm{S}}$ is the solution resistance, $C P E_{1}$ is an element of the first constant phase, $R_{1}$ is the specific resistance for the first time constant, $R_{2}$ is the solution and the corrosion product film resistance and $C P E_{2}$ establish the second element constant phase [24]. The first time constant $\left(\mathrm{R}_{1}-\mathrm{CPE}_{1}\right)$ is connected with bulk steel passive film interface controlling the dissolution of steel elements and also formation of passive film on stainless steel surface. The second time constant $\left(\mathrm{R}_{2}, \mathrm{CPE}_{2}\right)$ describes the passive film/saliva solution interface. This interface controls and at the same time slows down the corrosion degradation process.

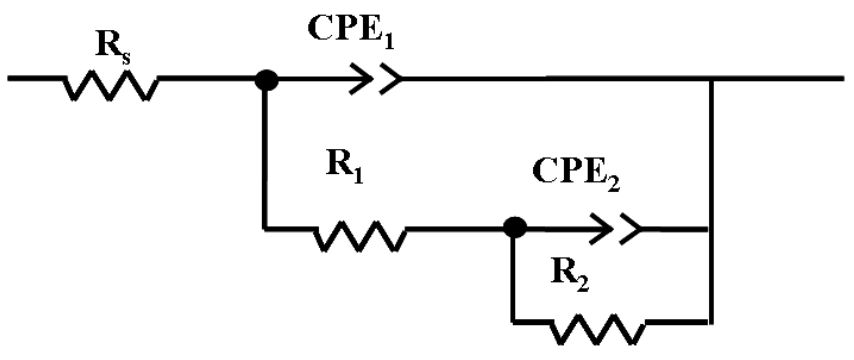

Fig. 5. The equivalent electrical circuits of AISI 316 Ltainless steel surface used for better fitting and simulation of electrochemical experimental measurements of the impedance spectra

The proposed equivalent electrical circuit fits well the Nyquist impedance experimental data but also the Bode plots and admittance plots as module $\mathrm{Z}$ versus frequency and phase element versus frequency. The Bode plots, Figure 6 (a) and (b) are displayed an acceptable agreement between experimental and simulated data, thereby validating the selected equivalent circuit model. 

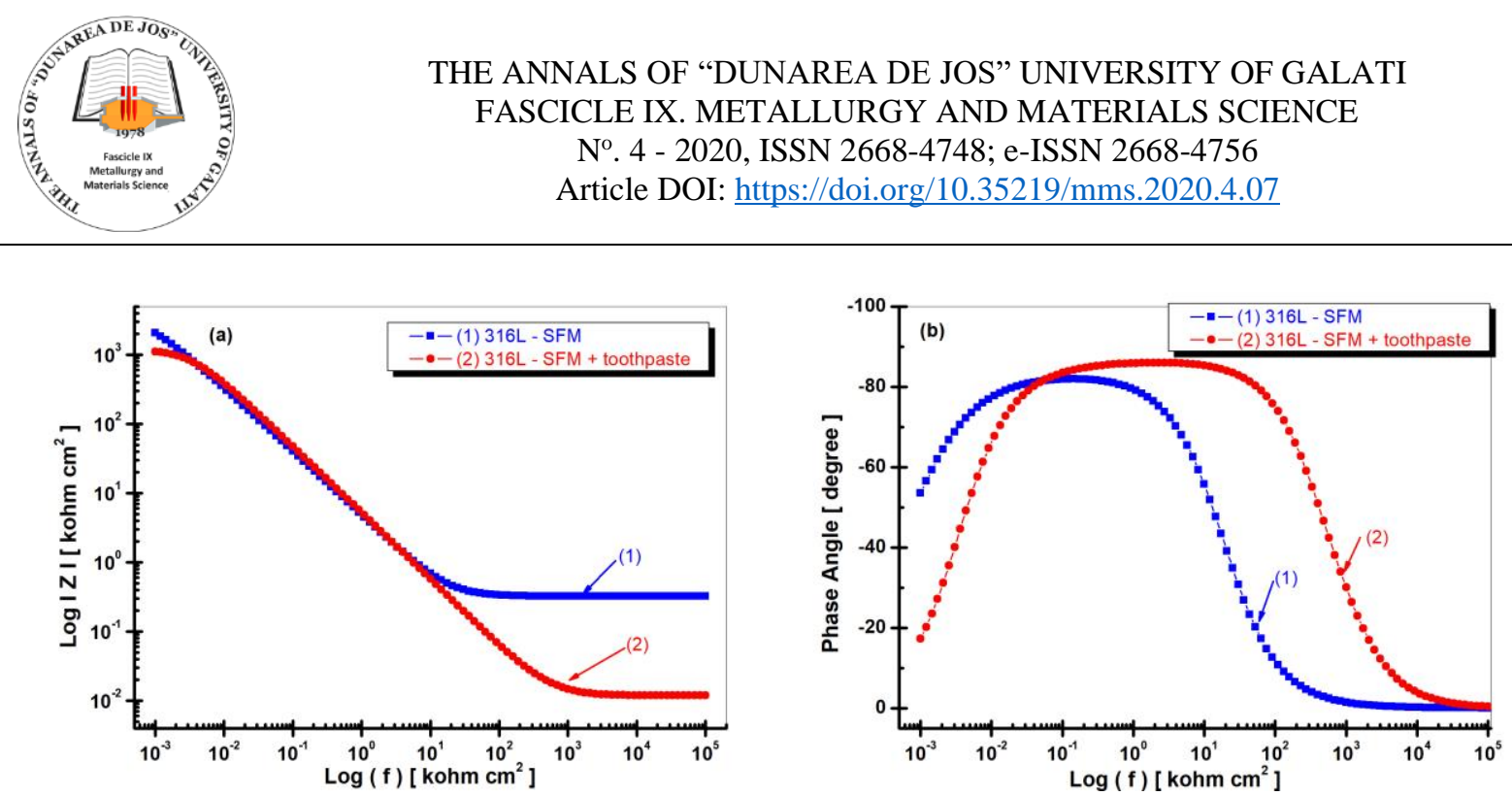

Fig. 6. Electrochemical Impedance Spectroscopy results (symbols) and fitting diagrams (plain lines) in the Bode coordinates for the AISI 316L stainless steel immersed in: (1) Fusayama Meyers saliva;

(2) Fusayama-Meyer saliva mixed with fluorinated toothpaste. (a) - module Z vs. logarithm of frequency and $(b)$ phase angle versus logarithm of frequency

Table 4 summarizes the values of the circuit parameters obtained from the best fit with the experimental impedance diagrams.

The results obtained after fitting the EIS data using the proposed equivalent circuit (EC), are describing major or minor differences between the two tested solutions. The $\mathrm{R}$ values showed on Nyquist impedance data from Figure 4 are values obtained by summing R1 and R2 for respective saliva solution. The $\mathrm{R}$ values for SFM solution and for SFM mixed with fluorinated toothpaste are of the same order of magnitude but with slower decrease for 316L stainless steel immersed in Fusayama Meyer saliva mixed with fluorinated toothpaste (about four time smaller) indicating a slower increasing of corrosion rate due to fluor ions containing the toothpaste.

Table 4. Fitted values for the different elements of the electrical equivalent circuits for the impedance experimental results of $316 \mathrm{~L}$ stainless steel immersed in Fusayama Meyer saliva with and without fluorinated toothpaste

\begin{tabular}{|c|c|c|c|c|c|c|}
\hline $\begin{array}{l}\text { Elements of the } \\
\text { equivalent circuit }\end{array}$ & $\begin{array}{c}\mathbf{R}_{1} \\
{\left[\mathrm{k} \Omega \mathrm{cm}^{2}\right]}\end{array}$ & $\begin{array}{c}\mathrm{CPE}_{1} \\
{\left[\mathrm{~F} \mathrm{~cm}^{-2}\right]}\end{array}$ & $\begin{array}{c}\mathbf{R}_{2} \\
{\left[\mathrm{k} \Omega \mathbf{c m}^{2}\right]}\end{array}$ & $\begin{array}{c}\mathrm{CPE}_{2} \\
{\left[\mathrm{~F} \mathrm{~cm}^{-2}\right]}\end{array}$ & $\alpha$ & $\begin{array}{c}\mathbf{R} \\
{\left[\mathrm{k} \Omega \mathrm{cm}^{2}\right]}\end{array}$ \\
\hline $\begin{array}{c}\text { Fusayama-Meyer } \\
\text { saliva }\end{array}$ & 129 & $4.38 \mathrm{E}-7$ & 4241 & $3.77 \mathrm{E}-5$ & 0.92 & 4370 \\
\hline $\begin{array}{c}\text { Fusayama-Meyer } \\
\text { saliva + fluorinated } \\
\text { toothpaste }\end{array}$ & 72 & $2.08 \mathrm{E}-5$ & 1128 & $1.20 \mathrm{E}-5$ & 0.88 & 1200 \\
\hline
\end{tabular}

Tables 4 indicates values of the $\alpha$ element of 0.92 with the tendency towards pure capacitive behavior for stainless steel immersed in Fusayama Meyer saliva. A slower value of $\alpha$ parameter of 0.88 is obtained after fitting the impedance results of $316 \mathrm{~L}$ stainless steel immersed in Fusayama Meyer saliva mixed with fluorinated toothpaste.

\section{Conclusion}

The study presents the corrosion behavior of AISI 316L stainless steel in Fusayama Meyer saliva and the effect of fluorinated toothpaste on corrosion resistance. The results of open circuit potential evolution reveal that AISI $316 \mathrm{~L}$ stainless steel immersed in Fusayama Meyer saliva show a passive state with the tendency to slow increase to more positive values as compared with the evolution of open circuit potential of stainless steel immersed in saliva mixed with toothpaste, which is shifted from the beginning of immersion to more negative values and the steady state value is stated at more negative value also.

Analyzing the linear polarization diagrams it is concluded that the corrosion potential is obtained at more negative value for AISI 316L Stainless Steel immersed in Fusayama Meyer saliva as compared with saliva mixed with fluorinated toothpaste, even if the corrosion current densities reveal the values of same order of magnitude. 
The polarization curves in the potentiodynamic regime denoted that the passive domain in the solution without the toothpaste is larger than those revealed in saliva mixed with fluorinated toothpaste.

From the Electrochemical Impedance Spectroscopy can be concluding that AISI 316L SS immersed in artificial Fusayama Meyer saliva have a higher value of specific polarization resistance as compared to human saliva mixed with toothpaste.

Therefore, the recommendations of dentists regarding dental brushing with fluorinated toothpaste for orthodontic patients require a readjustment of the oral hygiene products suggested with those without the fluorinated component.

\section{Acknowledgments}

The authors acknowledge the support of this work by the project ANTREPRENORDOC, in the framework of Human Resources Development Operational Programme 2014-2020 (POCU), financed from the European Social Fund under the contract number 36355/23.05.2019 HDR OP/380/6/13 - SMIS Code: 123847.

\section{Disclosure of interest}

The authors declare that they have no competing interest.

\section{References}

[1]. Dewangan A. K., Patel A. D., Bhadania A. G., Stainless steel for dairy and food industry: a review, J Material Sci Eng, 4: $1000191,2015$.

[2]. Ceschini L., Martini C., Rotundo F., Sliding contacts for the pharmaceutical industry: failure analysis and dry sliding tests for the replacement of hard Cr on AISI 316L steel, Tribol Int, 81: 248257, https://doi.org/10.1016/j.triboint.2014.09.004, 2015.

[3]. Asri R. I. M., Harun W. S. W., Samykano M., Lah N. A. C., Ghani S. A. C., Tarlochan F., Raza M. R., Corrosion and surface modification on biocompatible metals: A review, Mater Sci Eng C 2017, 77: 1261-1274, https://doi.org/10.1016/j.msec.2017.04.102.

[4]. Holmes D., Sharifi S., Stack M. M., Tribo-corrosion of steel in artificial saliva, Tribol Int, 75: 80-86. https://doi.org/10.1016/j.triboint.2014.03.007, 2014.

[5]. Simionescu N., Ravoiu A., Benea L., Electrochemical in-vitro properties of $316 \mathrm{~L}$ stainless steel for orthodontic applications, Rev Chim, 70: 1144-1148, 2019.

[6]. Tipanan Y., Pasutha T., Pintu C., Corrosion of metal orthodontic brackets and archwires caused by fluoride-containing products: Cytotoxicity, metal ion release and surface roughness, Orthod Waves, 77: 79-89, 2018.
[7]. Oshida Y., Sellers C. B., Mirza K., Farzin-Nia F., Corrosion of dental metallic materials by dental treatment agents, Mater Sci Eng C, 25: 343-348, 2005.

[8]. Anuwongnukroh N., Dechkunakorn S., Kanpiputana R., Oral hygiene behavior during fixed orthodontic treatment, Dentistry, 7: 1000457, DOI: 10.4172/2161-1122.1000457, 2017.

[9]. Sudjalim T. R., Woods M. G., Manton D. J., Prevention of white spot lesions in orthodontic practice: a contemporary review, Aust Dent J, 51: 284-289. doi: 10.1111/j.18347819.2006.tb00445.x, 2006.

[10]. Benyahia H., Ebntouhami M., Forsal I., Zaoui F., Aalloula E., Corrosion resistance of NiTi in fluoride and acid environments, Int Orthod, 7: 332-334, doi: 10.1016/S1761-7227(09)73506-5, 2009.

[11]. Kao C. T., Ding S. J., He H., Chou M. Y., Huang T. H., Cytotoxicity of orthodontic wire corroded in fluoride solution in vitro, Angle Orthod, 7: 7349-354, 2007.

[12]. Alavi S., Farahi A., Effect of fluoride on friction between bracket and wire, Dent Res J, 8: 37-42, 2011.

[13]. Toderascu G., Dumitrascu V., Benea L., Chiriac A., Corrosion behaviour and biocompatibility of 316 stainless steel as biomaterial in physiological environment, Fascicle IX. Metallurgy and Materials Science, 4: 16-22, 2015.

[14]. Hayes A., Sharifi S., Stack M. M., Micro-abrasioncorrosion maps of $316 \mathrm{~L}$ stainless steel in artificial saliva, J Bio \& Tribo-Corros, 1: 1-25, 2015.

[15]. Jiang R., Wang Y., Wen X., Chen C., Zhao J., Effect of time on the characteristics of passive film formed on stainless steel, Appl Surf Sci, 412: 214-222, 2017.

[16]. Benea L., Simionescu N., Effect of biological solution and pH on corrosion resistance of $304 L$ SS for dental brackets, Rev Chim, 71: 180-187. https://doi.org/10.37358/RC.20.4.8056, 2020. [17]. Benea L., Mardare E., Mardare M., Celis J. P., Preparation of titanium oxide and hydroxyapatite on Ti-6Al-4V alloy surface and electrochemical behavior in bio-simulated fluid solution, Corros Sci, 80: 331-338, 2014.

[18]. Cheng L., Moor S., Kravchuk O., Meyers I., Ho C., Bacteria and salivary profile of adolescents with and without cleft lip and/or palate undergoing orthodontic treatment, Aust Dent J, 52: 315-321, doi: 10.1111/j.1834-7819.2007.tb00508.x, 2007.

[19]. Dumitrascu V. M., Benea L., Improving the corrosion behavior of 6061 aluminum alloy by controlled anodic formed oxide layer, Rev Chim, 68: 77-80, 2017.

[20]. Bard A., Faulkner L., Electrochemical methods. Fundamentals and application, 2-nd. ed. New York: Wiley, 2001.

[21]. Lasia A., Modern Aspects of Electrochemistry, vol 32, ed White RE, Conway BE, Bockris JO'M, New York: Kluwer Academic Plenum Publishers, 1999.

[22]. Brug G. J., Van den Eeden A. L. G., Sluyters-Rehbach M., Sluyters J. H., The analysis of electrode impedances complicated by the presence of a constant phase element, J Electroanal Chem Interf Electrochem, 176: 275-295. https://doi.org/10.1016/S00220728(84)80324-1, 1984

[23]. Benea L., Danaila E., Ponthiaux P., Effect of titania anodic formation and hydroxyapatite electrodeposition on electrochemical behavior of Ti-6Al-4V alloy under fretting conditions for biomedical applications, Corros Sci, 91: 262-271. https://doi.org/10.1016/j.corsci.2014.11.026, 2015.

[24]. Ribeiro D. V., Souza C. A. C., Abrantes J. C. C., Electrochemical impedance spectroscopy (EIS) to monitoring the corrosion of reinforced concrete, Revista IBRACON de Estruturas e Materiais, 8: 529-546, 2015. 